\title{
The Operation Center of the Smart Community Centers on Data Zuoliang L $\mathrm{V}^{1, \mathrm{a}}$ and Baolong Yang ${ }^{2, \mathrm{~b}^{*}}$

\author{
${ }^{1}$ School of economics and management, Dalian University, Dalian 116622, China \\ ${ }^{2}$ School of economics and management, Dalian University, Dalian 116622, China \\ agtqyzx@163.net, byangbaolong2015@163.com,
}

Keywords: Smart community; Operation center; Big data; Data mining

\begin{abstract}
Smart community at the completion of the mobile Internet, cloud computing, big data and IOT framework platform and infrastructure construction, how to better later in the community management and service in the role, give full play to its real smart community management services and better provide considerable benefits for the developer, you need a fusion of various kinds of real-time data, information, and gathering all kinds of service agency, the wisdom of community operations center. This paper mainly discusses the wisdom of the data-centric community composition and the responsibility of the operations center, analyzed the community operations center the framework of data mining and its challenges in the process of construction.
\end{abstract}

\section{Introduction}

Real estate industry as the basis for the development of the national economy industry and pillar industry, to expand domestic demand, growth and livelihood plays an important role in promoting. Along with our country economy enters the new normal, real estate industry is also the reshuffle. In the "Internet + real estate" development strategy, development smart community become the direction of the many real estate companies seek breakthrough. For the traditional real estate development enterprises, the development and construction smart community hardware facilities have no problem, but how to through the smart community to realize higher profit than traditional community development is the need to solve a big problem. Smart community at the completion of the mobile Internet, cloud computing, big data and IOT framework platform and infrastructure construction, how to better later in the community management and service in the role, give full play to its real smart community management services and better provide considerable benefits for the developer, you need a fusion of various kinds of real-time data, information, and gathering all kinds of service agency, the wisdom of community operations center. Smart community operations center, which is the core of the smart community, will give the community running all kinds of data and information collection and monitoring, and for the government, enterprises and individuals to provide intelligent and personalized custom services [1].Smart community is discussed in this paper the main several management operation mode, and puts forward a data-centric smart community operation center, explores the operations center and infrastructure, the primary responsibility of the operations center is analyzed in the development process of the future faces many challenges.

\section{The Construction Status and Operation Mode of Smart Community}

Problems and trends of the smart community. Through investigation and research have been built pilot, the smart community residents to enjoy equal, efficient and convenient services, and to enhance the investment the enthusiasm of social service management, obvious effect, but as a result of our smart community construction is still in its infancy, there are many difficulties and problems also:

(1) lack of unified standards, the compatibility between the system and the open difference, resulting in the confusion of the macro, the information alone

The island and the repeated construction phenomenon are serious, the related resources cannot integrate the application. 
(2) lack of unified planning, management and coordination, the institutional mechanism is not smooth, and there are closed pipes between different participants

The coordination mechanism between departments has not yet been completed.

(3) the intelligent level of the system cannot meet the actual demand, and the public service project is inadequate and the use is inconvenient

The problem of publicity effect and light practical application.

(4) lack of capital and profit model, which is greatly influenced by construction cost and consumption level; Lack of a reasonable business model, lack of effective sustainable operation and management mechanism. The lack of professional skills, management, etc., lack of community service personnel, quality needs to be improved.

The development trend of future smart communities can be viewed from three aspects: in terms of technology, will show the flood in the network, intelligent information, system integration, digital equipment and design; From the perspective of service, it will show the benefits, practicality, convenience and diversity of service. In terms of management, the standardization, professionalism, controllability and flexibility of management will be more prominent.

The operation model of smart community. The construction and operation of the smart community should be based on in-depth needs analysis, to understand the needs of the parties to the smart community construction and operation planning, top-level design, system architecture and deployment reasonable, at the same time to clear the construction operation mode and investment plan. The smart community operation can continue to expand service areas, for the government, enterprises and the public to provide products and services in the smart community, to promote the healthy and sustainable development of the smart community, the wisdom of community building and smart city building effective fusion connection, avoid data island, the operation should not only pay attention to the economy, technical and local functions, should also pay attention to the wisdom of the city planning, integration capability, scalability, data exchange standards and information security standards and other factors, inspect the running mechanism of new technology is conducive to the effective and timely application, ensure that the community and city construction [2].

At present, research is mainly concentrated in the government led, through policy guidance, funding, contact suppliers, system integration, so that different network providers, community operators and other participants actively involved in the construction and operation of the smart community through investment funds, post operation and resource utilization etc. To sum up, the current wisdom community construction and operation mode mainly has the government as the main body, the enterprise as the main body and the government guidance, enterprise participation three kinds.

Taking the government as the main body refers to the integration and optimization of various application systems and the formation of the overall development of the industry through the relevant policies, tilt and guidance, process, organization and supervision throughout the process. Under the unified planning and overall management of the government, different enterprises are responsible for the collection of requirements information, the construction of the community, the construction of the system platform, the operation of the community, and the management of the property services. The biggest feature of this approach is that from the perspective of the whole social management and services, a complete community project construction planning, can well control the overall situation of the project construction and operation.

Taking enterprises as the main body refers to the construction and management of the project carried out by the enterprise. The biggest feature is the real estate developers in accordance with market demand and enterprise deployment, starting from the optimization of product structure, market share, improve the core competitiveness of enterprises and other needs, the smart community construction and operation of the project. This approach is mainly to promote the government's policy support by developers, to give full play to the role of market mechanisms, and fully develop the survival of the fittest environment. 
Government guidance and enterprise participation refer to the government led, operators responsible for specific construction and provide public pipes

A way of management and service. This way is usually by the government on a smart community project and social enterprises signed an agreement by the social enterprise community project financing, construction, operation and maintenance of the term of the agreement, and by social service organizations and enterprises to take part of the government public service. According to the different forms of the contract, after the expiration of the agreement, the social enterprise shall transfer the project gratis or paid to the government department. Although the government does not intervene in the organization, construction, services, macro management of social enterprises and effective supervision must maintain, to social service organizations to protect the community construction quality and operation period and the service quality of the enterprise.

In the management system of smart community, telecom operators, and supervision and management system to solve the formulated solution providers, data acquisition equipment manufacturers, system integrators, intelligent hardware providers, software providers, service providers, community and government policy users constitute the wisdom of the community industry network, sharing and strategic cooperation in the formation of the intelligent community system through each other's resources. Different enterprises play their respective advantages according to their respective related resources, and realize different service modes and profit models of enterprises. The key to the wisdom of the community operation of real estate development enterprises as the leading is to determine their position in the smart community value link, according to their own strategic layout and the actual situation, the integration and management of centralized resources of different participants. By the Fig. 1, we can see that the core of the smart community operation is data centric operating center. The traditional real estate development enterprises, commissioned by the post or the formation of a professional team is a good model for the management of operation of the smart community, the wisdom of the community is the operations center of mass data generated by users to focus on community management operations.
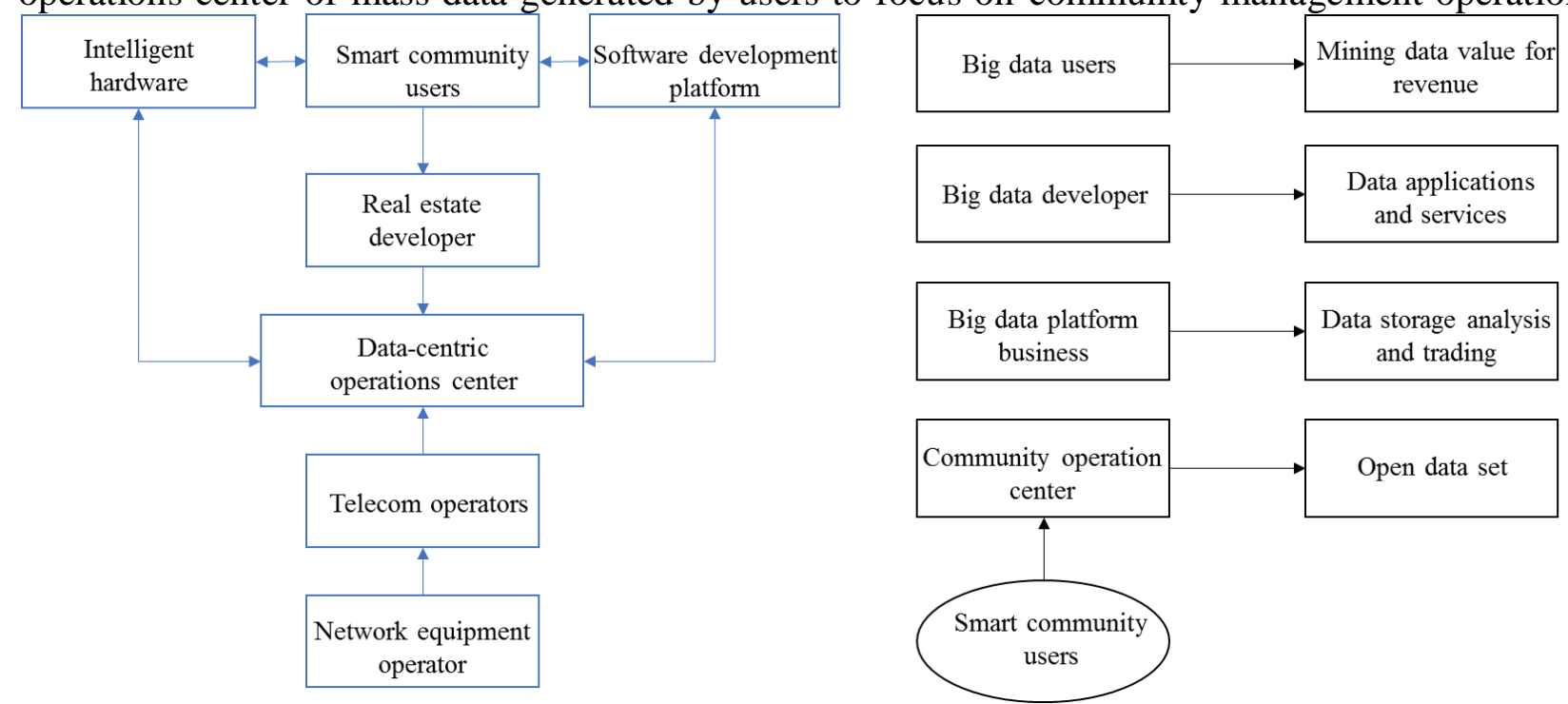

Figure 1. The diagrammatic sketch of smart community's operation model that dominated

Figure 2. The "Big data ecosystem" of smart community's operation model by the real estate developer

In the operation of the intelligent community, the community operation center needs to integrate and share community information resources, monitor the operation of the community in real time, and realize the coordination and command of the multi department. In the community management and service, promote the formation of the whole society the big data open applications, services and trading system, the formation of large data including public welfare and commercial processing, the 
level of application and service system based on perfect.

Smart community operations center is generally composed of big data centers, community operation monitoring and command center, community IT infrastructure operation and maintenance center, intelligent service center of 4 parts. Big data center will become the data operation of data pool and the hub of the Internet of things, to achieve real-time and comprehensive perception of community operating data. The community operation monitoring and command center will realize inter departmental, inter regional and inter system efficient collaboration and emergency response on the basis of real-time and comprehensive perception [3]. The community IT infrastructure operations and maintenance center is responsible for maintaining and updating the infrastructure of the smart community operating center, ensuring the safe and stable operation of the operations center throughout the day. In addition to providing services to the government, smart services will also provide services to businesses and the public in the city.

The government IT the traditional information architecture will gradually be replaced by the cloud - - "interactive smart community operations center, reduce construction and operation and maintenance of community information cost, greatly reduces the cost of operation, to enhance the efficiency of the community. The mode of government governance will also move from the community management to the community operation and service through the operation center.

It can be seen in Fig. 2, in the era of big data, all the wisdom of the community management services operations center will focus on data mining of massive data, continuous smart community user generated in the commercial value, and ultimately the formation of a new "big data ecosystem". Smart community operations center will be through model innovation, recycling a new brand of community management. Through the operation center, the visualization, intelligence, controllability, predictability and continuous optimization of community service operation can be realized.

\section{Smart Community Operational Center of the Big Data Challenge}

By massive sensors smart community operations center in the IOT will continue to collect huge amounts of data, and these data need to go through the storage, processing, query and analysis can be fully used for various applications, thus providing intelligence service, and large data storage, processing, query and analysis of the real-time requirements more and more high then, will bring about a series of problems and challenges.

(1) large data storage costs are too high. Storage technology development brought about by the decline in storage costs is far behind the speed of data growth, at this stage, in accordance with the ideal standard storage and preservation of all big data, there are still enormous obstacles to the cost. The rapid growth of the data scale and the resulting high cost have become important factors restricting the development of urban security and other systems. At present, most cities in China have to shorten the data storage time and reduce the quality of data storage to reduce construction costs, but this will seriously reduce the traceability and identification value of video data.

(2) the rapid retrieval of large data and the low degree of automation of information extraction. Traditional information systems only collect and store data, but lack of effective automatic extraction and analysis of key semantic information such as behavior. In the era of big data, especially the video data space, the rapid expansion of the scale of the traditional method to further highlight the difficulties, a variety of remote sensing of Earth Observation Satellite every day back to the ground level PB data in the city every day video acquisition EB level data, present complex semantic automatic analysis and understanding there are still obstacles. The big data in the city contained in the fall, and hovering over the wall, and a vehicle collision, retrograde and other abnormal behavior, the more important events and characteristics of information, can be identified and early warning, such as a major robbery before usually accompanied by the Capitol this kind of wandering behavior [4]. Efficient extraction of semantic information in the city of big data through 
the object and behavior recognition and retrieval automation technology, can be carried out early warning and effective deterrent to crime, to do beforehand prevention, real-time information and post timely disposal, finally makes the city emergency in people's life and property safety and daily production and living order a full range of security [4].

(3) it is very difficult to tap the rich knowledge in big data. Big data not only contains the data and information, but also implied rules and knowledge, and knowledge and rules in the data is not given directly, but through mining and analysis in depth, and big data due to their own characteristics to effective integration and management, it is difficult to automatic processing and analysis problems, especially is involved in space related data mining is very difficult. To mining and analysis of inherent rules and knowledge in the data, to solve the heterogeneous data retrieval and other issues, also need to address data screening, semantic description, semantic understanding, uncertainty, knowledge expression and a series of key technologies of [5]. At the same time, the effective and feasible data filtering, semantic understanding and semantic association can't be directly applied to large data, and at the same time, the laws and knowledge in big data can't be fully utilized.

\section{Summary and Prospect}

Smart community is based on digital city, the Internet of things and cloud computing to establish the fusion of the real world and digital world, in order to realize the perception of people and objects, control and intelligent service. Smart community to the transformation of economic development, urban intelligent management and intelligence services to the public has extensive prospect, thus making the development of man and nature more harmonious. The realization of the intelligent community operations center need to build more perfect information infrastructure and intelligence operations and technical support, to ensure that the application of various kinds of intelligent community can be used well and could afford. Smart community construction will produce large data problem is the next generation of frontier science, also is the driving force for promoting the development of the smart community brings new opportunities and challenges, it will need to be targeted to speed up the technical innovation and the key research about big data research, to promote and accelerate the development of service industry wisdom, to better and more intelligent application service the masses at the same time, make the city more scientific, efficient, low carbon and running safely. For real estate development enterprises, get rid of the current real estate market downturn dilemma and smart community in the later operation to realize the profit, to promote construction of intelligent community operation center is one big key.

\section{Acknowledgments}

This work is partially supported by National Natural Science Foundation of China No.71372120, Dalian city association of social science No. 2015dlskzd129, Dalian Jinzhou New District Science and Technology Project No. KXYJ-RKX-2015-001.

\section{References}

[1] J. Phahlamohlaka: Ifip Advances in Information \& Communication Technology, Vol.49(2014) No.3, p.253.

[2] K. Mase: Ieice Transactions on Communications, Vol.95(2012) No.6, p.1902.

[3] V.A. Elia: World Scientific Book Chapters, Vol.2(2016) No.3, p.51.

[4] K. Wu: Hebei Academic Journal, Vol.33(2013) No.5, p.113. (In Chinese)

[5] S.P. Li: Contemporary Finance \& Economics, (2003) No.7, p.76. (In Chinese) 